\title{
An Investigation of Associations Between Race, Ethnicity, and Past Experiences of Discrimination with Medical Mistrust and COVID-19 Protective Strategies
}

\author{
Andrea C. Smith ${ }^{1} \cdot$ Jacqueline Woerner ${ }^{1,2}$ (D) $\cdot$ Rochelle Perera $^{1} \cdot$ Angela M. Haeny $^{3} \cdot$ Jonathan M. Cox ${ }^{1}$
}

Received: 22 January 2021 / Revised: 4 May 2021 / Accepted: 1 June 2021 / Published online: 11 June 2021

(C) W. Montague Cobb-NMA Health Institute 2021

\begin{abstract}
This study investigates the associations between three forms of discrimination, race and ethnicity, general medical mistrust, health-specific COVID-19 conspiracy beliefs, and adherence to COVID-19 protective behaviors. Participants $(n=963)$ completed an online survey during May 2020, when stay-at-home orders and other government mandates were implemented in many states. Results indicate that everyday discrimination and healthcare discrimination were associated with significantly higher general medical mistrust, and healthcare discrimination and structural discrimination were associated with higher endorsement of health-specific COVID-19 conspiracy beliefs. Higher endorsement of health-specific COVID-19 conspiracy beliefs, but not general medical mistrust, was associated with significantly lower engagement in health-specific COVID-19 conspiracy beliefs. This study helps to contextualize racial health disparities during the COVID-19 pandemic and the widespread impact of everyday, structural, and healthcare discrimination in society.
\end{abstract}

Keywords Medical mistrust $\cdot$ COVID-19 $\cdot$ Discrimination $\cdot$ Health inequalities

COVID-19 has highlighted the systemic health and social inequalities affecting minoritized racial groups [1]. Some government officials and other Americans have racialized COVID-19 itself as the "Chinese" or "Wuhan" virus, a form of scapegoating which has given rise to several instances of xenophobic rhetoric and racist attacks on Asian and Asian American people [2, 3]. In addition, historically marginalized communities are shouldering the greatest burden of the disease at disproportionate rates [1, 4-9]. Price-Haywood and colleagues (2020) examined the hospitalization and mortality rates among Black and White patients who contracted the virus at Ochsner Health Center in Louisiana and found that $76.9 \%$ of hospitalized patients and $70.6 \%$ of patient deaths were Black, even though Black patients only made up 31\% of the hospital's population [4]. Black, American Indian, and

Jacqueline Woerner

jacqueline.woerner@ucf.edu

1 Department of Sociology, University of Central Florida, Orlando, FL, USA

2 Department of Psychology, University of Central Florida, Orlando, FL, USA

3 Yale School of Medicine, New Haven, CT, USA
Latinx individuals are also hospitalized for COVID-19 at higher rates than their Asian and White counterparts [10-12]. These minoritized racial groups' infection and mortality rates are substantially higher than their proportion to the population [7]. The CDC has indicated several potential reasons for these racial health disparities such as the occupation, housing, education, and wealth gap [1]. Many of these factors are symptoms of systemic inequalities in American society and may reflect structural and individual-level experiences of discrimination, poverty, and socioeconomic status [1, 13].

While recent studies have highlighted the existence of racial disparities in COVID-19, it is important to consider how factors such as discrimination and medical mistrust might contextualize these disparities [14]. Accordingly, the current study investigates whether race and ethnicity and experiences of discrimination-including healthcare, everyday (i.e., microaggressions), or structural discrimination - are associated with individuals' medical mistrust (general and healthspecific COVID-19 conspiracy beliefs) which is defined as the belief or expectation that a medical professional will act against one's best interest or well-being [15-17]. We further investigate how these factors relate to adherence to COVID19 protective behavior. An improved understanding of these social determinants may further raise awareness of inequalities and health disparities afflicting vulnerable populations. 


\section{Race, Discrimination, and Medical Mistrust}

Racial health disparities have been well-documented amidst the COVID-19 pandemic; however, such disparities are not specific to COVID-19. Black individuals are disproportionately affected by conditions such as cardiovascular disease and diabetes, compared to their White counterparts [18-20]. Given that race is a social construct [21-23], it is essential to identify social determinants and structures that underlie these disparities [24, 25]. Multiple studies note that societal and physical environments within systems, including discriminatory interpersonal interactions, have a large influence on individuals' health and health behavior [26-28]. To better understand how race and discrimination are associated with health disparities, we must consider both the historical and modernday context in which these factors operate and the implications they have for mistrust of systems including the medical institution [29].

Medical mistrust is an umbrella term encompassing both general feelings of mistrust in the medical institution as a whole [30] and mistrust specific to one disease or context (e.g., COVID-19) [31]. Medical mistrust broadly as well as mistrust specific to COVID-19 is important to consider when seeking to understand racial disparities and health outcomes during the COVID-19 pandemic. Studies have reported higher levels of general medical mistrust among Black and Latinx communities compared to White ${ }^{1}$ communities [32-34]. Further, compared to White patients, Black patients report lower trust of physicians [35], and Latinx patients report higher fear of being tested on unwillingly [36]. The mistrust experienced within these communities is essential to address, as these groups are likely to experience harmful health behaviors linked to medical mistrust such as poorer management of health conditions [37], lower adherence to prescriptions and medical recommendations [29,35], lower utilization of healthcare services [38, 39], and decreased participation in preventative care [38].

The root cause of mistrust of the healthcare system by minoritized groups is multifactorial [40]. Many studies have linked Black Americans' mistrust to knowledge of historical medical malpractice such as the Tuskegee experiments that took place between 1932 and 1972 [36, 41], but medical abuse of minoritized racial groups was pervasive both before and after this experiment $[25,42]$. Some notable examples include Dr. Sims' experimentation on enslaved Black women in order to "treat" vesicovaginal fistula without anesthesia in the 1840 s [25]; the involuntary sterilization of Black women in the 1960s, termed Mississippi Appendectomy [25]; experimenting on Black women to perfect the C-section in the 1830s [25]; involuntarily injecting inmates with HeLa

\footnotetext{
${ }^{1}$ In this paper, "White" and "Black" are used to indicate White non-Latinx and Black non-Latinx identity, respectively.
}

cells to test cancer immunity in the 1950s [43]; and the involuntary testing of artificial blood on patients in the 2000s [25]. Medical malpractice and scientific racism still plague modern medicine today. In 2020, aboriginal women in Canada and women detained at the US border were subjected to involuntary sterilization [44-46]. These extreme events are not the sole example of contemporary malpractice. For instance, physicians are less likely to prescribe pain medication to Black patients, potentially due to a widespread inaccurate belief that Black individuals have a higher pain tolerance than other racial groups [47]. Black patients are also more likely to receive lower quality care for heart disease, cancer, HIV, and prenatal care than their White counterparts, if they are treated at all [48, 49]. These past and ongoing events significantly reduce Black patients' trust in medical professionals and medical institutions [25]. In the current study, we expect that marginalized racial groups, in particular Black Americans given this historical and modern-day context, will report greater medical mistrust.

Health-specific conspiracy theory beliefs have been cited as a facet of medical mistrust [31]. These conspiracy theories are characterized by the belief that medical organizations or the government is planning to do something harmful to certain groups $[15,50]$. For example, during the HIV/AIDS pandemic, conspiracy theories suggested the virus was invented to kill Black communities [51]. People who endorse these conspiracy theories may also believe that the government has the cure to cancer, but they are not telling citizens [50]. Similar theories were endorsed for Ebola [31] and now COVID-19. When COVID-19 first began in the United States, some conspiracy theorists believed it was a biological weapon made by the Chinese government or a virus made to control the population [50]. Although some of these conspiracy beliefs may sound outlandish to those who do not endorse them, it is important to note that there are reasons why people believe them. These beliefs are rooted in the same structural inequities outlined above that lead to more general forms of medical mistrust, often reflecting longstanding power differentials between higher and lower status groups [15, 52]. Davis and colleagues (2018) noted race-based conspiracy beliefs are inspired by conspiracies that have been proven to be true such as the Tuskegee experiment and the eugenics movement, implying that some conspiracy beliefs are grounded in historical reality [53]. Accordingly, in the current study, we aim to investigate the influence of race and experiences of discrimination on the endorsement of conspiracy beliefs specific to the COVID-19 pandemic.

Experiences of discrimination are central to understanding the potential association between race and individuals' experiences of medical mistrust, including the endorsement of COVID-19 conspiracy beliefs. Extant research shows that past discrimination inside and outside of the medical sphere drives mistrust $[35,51,54,55]$. Specific to healthcare settings, 
Shavers and colleagues (2012) found that both Latinx and Black patients experienced discrimination, such as being treated after a White patient despite waiting longer, medical personnel attending to White patients and ignoring Latinx patients, having different visitation rules for Latinx and White families, allowing White patients to be seen despite not having an appointment, and Black women being referred to as "you people" when being treated [33]. These experiences of discrimination have been associated with both general medical mistrust and conspiracy beliefs in Black and Latinx communities [53, 56, 57]. In fact, one study found that perceived racism in healthcare settings was the most robust predictor of Black men's medical mistrust, even after controlling for various background and health-relevant experiences [38]. More broadly, research also indicates that structural and everyday discrimination are more prevalent among minoritized racial groups, Black Americans in particular [25, 58].

Consequently, both structural discrimination and everyday discrimination are associated with increased medical mistrust and the endorsement of health-related conspiracy beliefs [54, 57, 59]. Many studies have evaluated discrimination as a singular construct $[37,60]$. Some exceptions have found that everyday discrimination, perceived racism in healthcare, and medical mistrust jointly contribute to preventive health screening delays among Black men [30]. Although everyday, structural, and healthcare discrimination are interrelated, they represent a range of experiences that exist within multiple levels and systems within our society $[58,61]$. Therefore, in the current study, we consider each of these forms of discrimination separately. Given that limited research has evaluated these different constructs representing discrimination separately, we do not advance hypotheses regarding their relative impact on general medical mistrust and health-specific COVID-19 conspiracy beliefs.

Most studies that have focused on racial disparities and medical mistrust tended to concentrate on Black and Latinx communities and have been framed as comparisons to nonLatinx White Americans [62]. However, fewer studies directly assess mistrust in the Asian and American Indian communities, despite also experiencing discrimination in the United States [63-66]. Existing research indicates that American Indian individuals report higher levels of medical mistrust and lower satisfaction with healthcare compared to White participants [67], whereas research on medical mistrust among Asian communities seems to be even more limited [68]. It is also important to acknowledge the intersection of race and ethnicity and consider individuals who hold multiple marginalized identities (e.g., Black-Latinx individuals) when evaluating various forms of discrimination, medical mistrust, and belief in conspiracy theories. Based on research and the context of discrimination in American society [69], we expect to find that Black participants will report the highest rates of discrimination, general medical mistrust, and health-specific
COVID-19 conspiracy beliefs. Due to the lack of literature examining discrimination and medical mistrust, we do not advance hypotheses regarding specific group comparisons, but expect that other marginalized racial groups (e.g., Latinx, American Indian) will also report experiences of past discrimination and endorse general medical mistrust and health-specific COVID-19 conspiracy beliefs.

\section{Implications of Medical Mistrust and COVID-19 Conspiracy Theory Beliefs}

Although the acknowledgement and understanding of racist historical medical events, current medical events, and discrimination partially explain medical mistrust, it is necessary to recognize how this negatively affects marginalized communities $[37,70]$. Medical mistrust is not the fault of the communities affected; rather, fault lies with the overlapping systems of discrimination that result in mistrust [37, 70]. It is imperative to acknowledge that health outcomes and behavioral manifestations of this mistrust are also a reflection of these systems of discrimination. In the context of COVID-19, it is therefore possible that greater medical mistrust, including greater endorsement of COVID-19 conspiracy theories, could result in reduced adherence to protective behavior such as maintaining physical distance, avoiding larger gatherings, and wearing a mask. In other words, a lack of trust in the government, healthcare providers, and other agencies of authority, partially due to negative and discriminatory experiences with these systems in the past, may result in individuals disbelieving or ignoring guidelines and recommendations to prevent against COVID-19 infection and transmission. Better understanding these associations between race, various forms of discrimination, medical mistrust, and engagement in COVID-19 protective behavior will ultimately provide greater insight into the context for racial and ethnic health disparities. Further, raising awareness of medical mistrust and belief in conspiracy theories within marginalized groups could lead to a more nuanced understanding of what future interventions could target in medical institutions to gain back the trust of marginalized groups in America.

\section{Data and Methods}

\section{Sampling and Procedures}

Data collection took place during the first 2 weeks of May 2020, when most states enacted stay-at-home orders and other government mandates [71, 72]. Participants were recruited from Amazon Mechanical Turk (MTurk) using CloudResearch pro features to enhance data quality. Participants were eligible if they were 18 years of age or older 
and lived in the United States. Interested participants were directed to the survey hosted on Qualtrics and were provided with an IRB-approved explanation of research and, if they consented to participate, proceeded with the study. A total of 990 participants completed the survey.

\section{Measures}

\section{Race and Ethnicity}

Participants self-identified their race with the option to specify their origin (e.g., if a participant identified as American Indian, they were able to specify Navajo Nation) although national origin categories were collapsed by race for analyses (e.g., if participant identified as Japanese, they were coded as Asian). Participants were also asked to specify whether or not they identified as Hispanic/Latinx and, if so, specify their origin (e.g., Puerto Rican). Individuals who identified with multiple racial identities were coded in accordance with the algorithm developed by the Census Bureau and used by the National Epidemiologic Survey on Alcohol and Related ConditionsIII (NESARC-III) for coding multiracial individuals with the exception of the coding of Hispanic/Latinx individuals [73]. White and Black participants were separated by Hispanic/Latinx ethnic identity, but other racial groups were not due to low frequencies, and participants who identified with another race and Hispanic/Latinx identity were coded only as the race they reported for the purposes of this study (e.g., Asian and Hispanic/Latinx were coded as Asian).

\section{Socioeconomic Status}

Socioeconomic status was assessed with three items. First, participants reported their annual household income on a scale from "Less than $\$ 10,000$ " to " $\$ 100,000$ " in $\$ 10,000$ increments (e.g., \$30,000-\$39,999). For analyses, income was dichotomized such that $0=$ less than $\$ 50,000$ and $1=\$ 50,000$ or higher. Participants also reported their highest level of completed education, ranging from "Did not complete high school" to "Professional degree (MD, DDS., JD, etc.) or doctoral degree $(\mathrm{PhD})$." For analyses, education was dichotomized such that $0=$ less than bachelor's degree and $1=$ bachelor's degree or higher. Finally, participants reported their subjective social status on a scale from 1 to 10 using the MacArthur Scale of Subjective Social Status [74]. Each indicator of socioeconomic status was included separately as a covariate in the full path model analysis.

\section{Everyday Discrimination}

Participants' experiences of everyday discrimination were assessed using the Everyday Discrimination Scale (EDS) [61], which assesses the frequency of 9 common experiences of discrimination (e.g., threatened or harassed, treated with less respect than other people) on a scale ranging from $1=$ never to $6=$ almost every day. Scores across the 9 items were averaged such that higher scores indicate a greater frequency of discrimination (alpha $=0.95$ ). For participants who reported any discrimination experiences, a tenth item assessed their primary attribution for their experiences, such as "ancestry or national origin," "race," and "skin color."

\section{Structural Discrimination}

Participants' experiences of structural discrimination were assessed using the Major Experiences of Discrimination Scale (MEDS) [61], which assesses the frequency of 9 common experiences of discrimination reflective of structural racism, e.g., denial of a promotion and discouragement from continuing education. To be consistent with the EDS, participants reported the frequency of each experience on a scale ranging from $1=$ never to $6=$ almost every day. Scores across the 9 items were averaged such that higher scores indicate a greater frequency of discrimination (alpha $=0.96$ ). For participants who reported any discrimination experiences, a tenth item assessed their primary attribution for their experiences, such as "ancestry or national origin," "race," and "skin color."

\section{Healthcare Discrimination}

Healthcare discrimination attributed to race and ethnicity, and income and education level was assessed with four items: (1) How often have you experienced discrimination in ability to obtain healthcare because of your race or ethnicity? (2) How often have you experienced discrimination in ability to obtain healthcare because or your income or education level? (3) How often have you experienced discrimination in how you were treated when you got care because of your race or ethnicity? (4) How often have you experienced discrimination in how you were treated when you got care because of income or education level? Race/ethnicity items are taken from the NESARC-III [73]. Items were assessed on a 5-point scale with response options ranging from $1=$ never to $5=$ very often and were averaged with higher scores indicating more frequent race-/ethnicity-based healthcare discrimination (alpha $=0.90$ ).

\section{General Medical Mistrust}

Medical mistrust was assessed with the 7-item Medical Mistrust Index (MMI) in which participants rated their agreement with statements (e.g., "You'd better be cautious when dealing with healthcare organizations") reflecting mistrust in medical organizations on a scale from $1=$ strongly disagree to $5=$ strongly agree [39]. Scores across the 7 items were averaged such that higher scores are indicative of more medical mistrust (alpha $=0.85$ ). 


\section{Health-Specific COVID-19 Conspiracy Beliefs}

Participants' endorsement of COVID-19 conspiracy theories was assessed with an adapted version of a measure previously used to assess conspiracy beliefs related to the HIV and Ebola pandemics $[31,75]$. Participants rated their agreement with four statements (e.g., "There is a cure for COVID-19, but the government isn't telling us.") on a scale from $1=$ strongly disagree to $5=$ strongly agree. Scores across the items were averaged such that higher scores are indicative of higher endorsement of COVID-19 conspiracy theories (alpha $=0.90$ ).

\section{COVID-19 Protective Behavior}

Participants' use of COVID-19 protective behaviors was assessed with a checklist of eight behavioral strategies, seven of which were provided based on the recommendations given by the CDC at the time [12] (e.g., "Avoid crowded places," "Wear protective gear such as a face mask or gloves," "Isolate yourself if you have symptoms," "stay at home/avoid going out in public," "Keep your distance from others (at least 6 feet)," "Quarantine yourself even if you don't have symptoms," and "Change school or work arrangements") and an eighth option for participants to identify additional strategies used. Given that one strategy, "Isolate yourself if you have symptoms," was only possible if participants had experienced symptoms, only endorsement of either this item or "Quarantine yourself even if you don't have symptoms" (but not both) was included in participants' total count score. In other words, if participants selected neither of these two options, it counted as zero checks, and if they chose either or both options, it counted as one - such that scores for COVID19 protective behaviors could range from 0 to 7 .

\section{Analytic Plan}

As an initial step, descriptive statistics including means and standard deviations and bivariate correlations for discrimination, medical mistrust, conspiracy beliefs, and COVID-19 distancing behaviors were evaluated. We also assessed frequencies of experiences relevant to individuals' health and pandemic-related experiences, such as getting tested for COVID-19 and experiencing symptoms. We evaluated these experiences for the full sample as well as separately for each racial group included in the analyses. We then assessed the full model depicted in Figure 1 in stages.

We evaluated the moderation hypotheses to determine if the relationships between discrimination, general medical mistrust, and health-specific COVID-19 conspiracy beliefs differed based on participants' race and ethnicity. Finally, we assessed the full path model with COVID-19 protective behaviors specified as a count variable and Black specified as the reference group, excluding any nonsignificant interactions from the previous analytic step in order to aid with the interpretation of main effects and to present a more parsimonious model. Three indicators of socioeconomic status (annual household income, highest level of education completed, and subjective social status) were included as covariates in analyses, as extensive research has shown that individuals' socioeconomic standing is associated with racial identity [76, 77], discrimination [78], and medical mistrust [79].

\section{Results}

\section{Descriptive and Preliminary Analyses}

Given the focus of race and ethnicity, participants who did not report their race and ethnicity $(n=19)$ were not included in analyses. Further, given the small group size, participants who identified as Native Hawaiian/Pacific Islander $(n=8)$ were excluded from analyses. White and Black participants were separated by ethnicity, but the same could not be done for other racial groups because of small sample size which limits the ability to derive reliable statistical estimates and contributes to unequal group sizes that diminish statistical power $(n<$ 24 for each group). The final sample included 963 participants with race and ethnicity self-reported as follows: 231 Black (non-Latinx), 72 Black-Latinx, 274 Asian, 217 White (nonLatinx), 115 White-Latinx, and 54 American Indian or Alaska Native.

Participants ranged between 18 and 80 years of age $(M=$ $35.00, S d=11.99)$, and $58.2 \%(n=560)$ identified as a woman $\left(4\right.$ transgender, 556 cisgender $\left.^{2}\right), 40.3 \%(n=388)$ identified as a man (12 transgender, 376 cisgender), and $1.5 \%(\mathrm{n}=15)$ identified as genderqueer, genderfluid, or another gender identity. The majority $(76.7 \%)$ of participants have lived in the United States their entire life, and $91.5 \%$ reported that they are a US citizen. Median household income was $\$ 50,000-\$ 59,999,59.5 \%$ of the sample held a bachelor's degree or higher level of education, and the mean subjective social status on a 10-point scale (10 indicating the highest social status, 1 indicating the lowest social status) was 5.50 $(S d=1.91)$. Descriptive information for socioeconomic status separated by race is presented in Supplemental Table A.

Prior to hypothesis testing, bivariate correlations were assessed (see Table 1). All forms of discrimination were significantly positively associated with medical mistrust and health-specific COVID-19 conspiracy beliefs, as well as negatively associated with engagement in COVID-19 protective behavior. Health-specific COVID-19 conspiracy beliefs were associated with decreased engagement in COVID-19

\footnotetext{
${ }^{2}$ Cisgender indicates gender identity corresponds to sex assigned at birth; transgender indicates gender identity does not correspond to sex assigned at birth.
} 
Fig. 1 a Hypothesized conceptual model, $\mathbf{b}$ final model with standardized path coefficients. Note: $* p<0.01, * * p$ $<0.001(N=963)$

a)
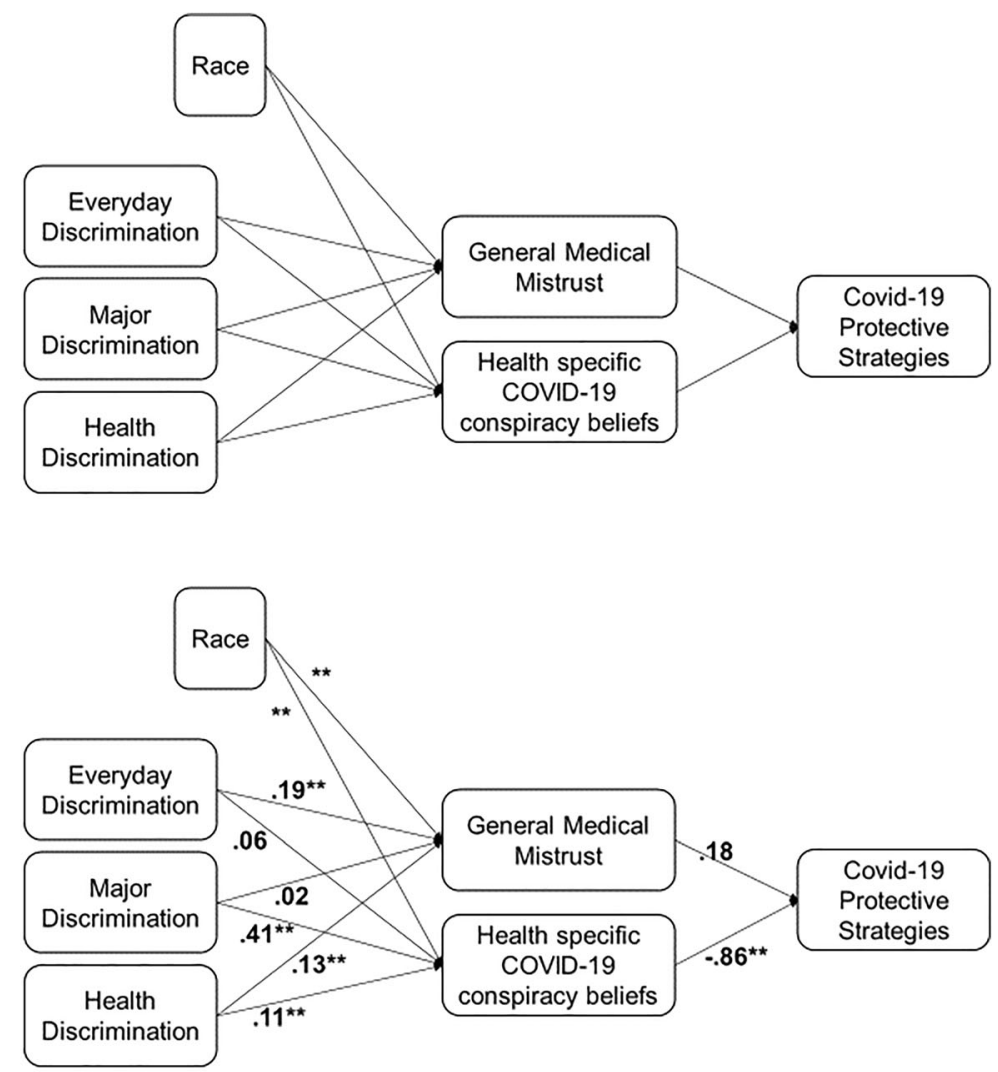

b)

protective behaviors, but general medical mistrust was not associated with these behaviors. Means and standard deviations for each variable for the full sample and separated by race and ethnicity are presented in Table 2, as well as one-way ANOVAs to assess differences between race and ethnicity groups. We also assessed the frequency of COVID-19 testing, experiencing symptoms, being an essential employee, having health insurance, being unable to see a doctor for medical care due to cost in the past year, having a chronic illness or disability, being immunocompromised, and knowing someone who has had COVID-19, again for the full sample and separated by race (Table 3). The most reported attribution for everyday discrimination and structural discrimination was race, with $32.9 \%$ and $33.2 \%$ of participants reporting discrimination selecting race as the primary reason, respectively.

\section{Moderation Analyses}

A series of moderation analyses were conducted. Mplus version 7.11 [80] was used to test the interaction between race and ethnicity and discrimination on general medical mistrust and health-specific COVID-19 conspiracy beliefs. Race was dummy coded with Black as the reference group, and separate analyses were conducted to assess the interaction with each type of discrimination (everyday, structural, and health discrimination) on general medical mistrust and health-specific COVID-19 conspiracy beliefs, respectively. Contrary to what we hypothesized, none of these interactions were significant ( $p>0.05$ for all interaction terms), indicating that the strength of the association between past discrimination and medical mistrust did not differ based on participants' race or ethnicity.
Table 1 Bivariate correlations for the full sample $(N=963)$

\begin{tabular}{lllllll}
\hline & 1 & 2 & 3 & 4 & 5 & 6 \\
\hline 1. Everyday discrimination & - & & & & & \\
2. Structural discrimination & $0.74^{* *}$ & - & & & & \\
3. Healthcare discrimination & $0.65^{* *}$ & $0.69^{* *}$ & - & & & \\
4. General medical mistrust & $0.33^{* *}$ & $0.28^{* *}$ & $0.31^{* *}$ & - & & \\
5. Health-specific COVID-19 conspiracy beliefs & $0.48^{* *}$ & $0.57^{* *}$ & $0.49^{* *}$ & $0.46^{* *}$ & - & \\
6. COVID-19 protective behaviors & $-0.22^{* *}$ & $-0.33^{* *}$ & $-0.24^{* *}$ & -0.06 & $-0.23^{* *}$ & - \\
\hline
\end{tabular}

Note: $* p<0.01, * * p<0.001$ 
Table 2 Means and standard deviations for key study variables for full sample and by race/ethnicity $(N=963)$

\begin{tabular}{|c|c|c|c|c|c|c|c|c|c|}
\hline & $\begin{array}{l}\text { Full } \\
\text { sample } \\
M(S d)\end{array}$ & Black & $\begin{array}{l}\text { Black- } \\
\text { Hispanic/ } \\
\text { Latinx }\end{array}$ & White & $\begin{array}{l}\text { White- } \\
\text { Hispanic/ } \\
\text { Latinx }\end{array}$ & Asian & $\begin{array}{l}\text { American Indian/ } \\
\text { Alaska Native }\end{array}$ & $F$ & $p$ \\
\hline Everyday discrimination & $2.47(1.20)$ & $2.49(1.77)$ & $3.60(1.35)^{*}$ & $2.28(1.14)$ & $2.57(1.27)$ & $2.21(1.03)$ & $2.67(1.17)$ & 18.30 & $<0.001$ \\
\hline Structural discrimination & $1.81(1.15)$ & $1.83(1.02)$ & $3.29(1.58)^{*}$ & $1.74(1.08)$ & $1.82(1.16)$ & $1.44(0.80)^{*}$ & $1.95(1.73)$ & 35.18 & $<0.001$ \\
\hline Healthcare discrimination & $1.80(0.93)$ & $1.99(0.92)$ & $2.73(1.28)^{*}$ & $1.58(0.80)^{*}$ & $1.81(0.91)$ & $1.53(0.70)^{*}$ & $1.99(0.95)$ & 26.76 & $<0.001$ \\
\hline General medical mistrust & $3.37(0.79)$ & $3.55(0.76)$ & $3.85(0.57)^{*}$ & $3.22(0.80)^{*}$ & $3.34(0.82)$ & $3.19(0.76)^{*}$ & $3.52(0.77)$ & 13.27 & $<0.001$ \\
\hline $\begin{array}{l}\text { Health-specific COVID-19 } \\
\text { conspiracy beliefs }\end{array}$ & $2.30(1.12)$ & $2.55(1.13)$ & $3.25(1.03)^{*}$ & $1.95(1.04)^{*}$ & $2.36(1.14)$ & $2.04(1.01)^{*}$ & $2.58(1.08)$ & 22.65 & $<0.001$ \\
\hline $\begin{array}{l}\text { COVID-19 protective } \\
\text { behaviors }\end{array}$ & $4.15(1.53)$ & $4.16(1.46)$ & $3.64(1.78)$ & $4.01(1.55)$ & $4.16(1.74)$ & $4.64(1.62)$ & $3.35(1.73)^{*}$ & 10.64 & $<0.001$ \\
\hline
\end{tabular}

*Differs from Black participants at $p<0.05$

Therefore, interaction terms were dropped from subsequent analyses to aid the interpretation of the main effects of race and ethnicity and past experiences of discrimination in the full model.

\section{Path Analysis}

Path analyses were conducted using Mplus version 7.11 [81]. As shown in Figure 1b, we investigated the main effects of three forms of discrimination (everyday, structural, and healthcare) as well as race (dummy coded with Black as the reference group) on general medical mistrust and healthspecific COVID-19 conspiracy beliefs and, in turn, the impact of general medical mistrust and health-specific COVID-19 conspiracy beliefs on COVID-19 protective behaviors. Statistical significance was determined through $95 \%$ confidence intervals; intervals that do not contain zero are statistically significant at $p<0.05$. Results indicated that everyday discrimination $(p<0.001)$ and healthcare discrimination $(p=$ $0.004)$ were associated with higher general medical mistrust, but structural discrimination ( $p=0.675)$ was not associated with general medical mistrust. Further, structural discrimination $(p<0.001)$ and healthcare discrimination $(p=0.003)$ significantly predicted higher endorsement of health-specific COVID-19 conspiracy beliefs, but everyday discrimination ( $p$ $=0.135$ ) was not associated with these beliefs.

Table 3 Frequencies for COVID-19-related experiences for full sample and by race/ethnicity $(N=963)$

\begin{tabular}{|c|c|c|c|c|c|c|c|}
\hline & Full sample & Black & $\begin{array}{l}\text { Black-Hispanic/ } \\
\text { Latinx }\end{array}$ & White & $\begin{array}{l}\text { White-Hispanic/ } \\
\text { Latinx }\end{array}$ & Asian & $\begin{array}{l}\text { American Indian/Alaska } \\
\text { Native }\end{array}$ \\
\hline \multicolumn{8}{|l|}{ Ever tested } \\
\hline Yes & $91(9.4 \%)$ & $23(10.0 \%)$ & $25(34.7 \%)$ & $17(7.8 \%)$ & $10(8.7 \%)$ & $6(2.2 \%)$ & $10(18.5 \%)$ \\
\hline $\begin{array}{l}\text { No-requested not re- } \\
\text { ceived }\end{array}$ & $60(6.2 \%)$ & $9(3.9 \%)$ & $9(12.5 \%)$ & $16(7.4 \%)$ & $8(7.0 \%)$ & $13(4.7 \%)$ & $5(9.3 \%)$ \\
\hline No-not requested & $812(84.4 \%)$ & $199(86.1 \%)$ & $38(52.8 \%)$ & $184(84.8 \%)$ & $97(84.3 \%)$ & $255(93.1 \%)$ & $39(72.2 \%)$ \\
\hline \multicolumn{8}{|l|}{ Symptoms } \\
\hline Yes-current & $37(3.8 \%)$ & $6(2.6 \%)$ & $12(16.7 \%)$ & $6(2.8 \%)$ & $7(6.1 \%)$ & $3(1.1 \%)$ & $3(5.6 \%)$ \\
\hline Yes-previous & $113(11.7 \%)$ & $16(6.9 \%)$ & $12(16.7 \%)$ & $33(15.2 \%)$ & $20(17.4 \%)$ & $33(15.2 \%)$ & $8(14.8 \%)$ \\
\hline No & $812(84.4 \%)$ & $209(90.5 \%)$ & $48(66.7 \%)$ & $178(82.0 \%)$ & $88(76.5 \%)$ & $178(82.0 \%)$ & $43(79.6 \%)$ \\
\hline \multicolumn{8}{|l|}{ Essential employee } \\
\hline Yes & $229(23.9 \%)$ & $50(21.8 \%)$ & $17(23.9 \%)$ & $57(26.3 \%)$ & $34(29.6 \%)$ & $55(20.1 \%)$ & $16(30.2 \%)$ \\
\hline No & $477(49.8 \%)$ & $118(51.5 \%)$ & $33(46.5 \%)$ & $104(47.9 \%)$ & $51(44.3 \%)$ & $152(55.7 \%)$ & $19(35.8 \%)$ \\
\hline Unsure & $85(8.9 \%)$ & $23(10.0 \%)$ & $9(12.7 \%)$ & $20(9.2 \%)$ & $10(8.7 \%)$ & $16(5.9 \%)$ & $7(13.2 \%)$ \\
\hline Not employed & $167(17.4 \%)$ & $38(16.6 \%)$ & $12(16.9 \%)$ & $36(16.6 \%)$ & $20(17.4 \%)$ & $50(18.3 \%)$ & $11(20.8 \%)$ \\
\hline \multicolumn{8}{|l|}{ Health insurance } \\
\hline Yes & $804(83.8 \%)$ & $184(80.3 \%)$ & $58(80.6 \%)$ & $185(85.3 \%)$ & $95(82.6 \%)$ & $245(89.7 \%)$ & $37(69.8 \%)$ \\
\hline \multicolumn{8}{|c|}{ Unable to see Dr. due to cost } \\
\hline Yes & $226(23.6 \%)$ & $47(20.5 \%)$ & $33(45.8 \%)$ & $53(24.5 \%)$ & $29(25.5 \%)$ & $46(16.8 \%)$ & $18(34.0 \%)$ \\
\hline \multicolumn{8}{|c|}{ Chronic illness or disability } \\
\hline Yes & $194(20.9 \%)$ & $52(23.7 \%)$ & $25(34.7 \%)$ & $56(26.3 \%)$ & $20(18.3 \%)$ & $26(9.8 \%)$ & $15(30.6 \%)$ \\
\hline \multicolumn{8}{|l|}{ Immunocompromised } \\
\hline Yes & $58(6.4 \%)$ & $19(8.9 \%)$ & $5(7.1 \%)$ & $14(7.1 \%)$ & $9(8.3 \%)$ & $4(1.5 \%)$ & $7(14.0 \%)$ \\
\hline \multicolumn{8}{|c|}{ Know anyone with COVID-19 } \\
\hline Yes & $355(36.9 \%)$ & $75(32.5 \%)$ & $32(44.4 \%)$ & $77(35.5 \%)$ & $52(45.2 \%)$ & $99(36.1 \%)$ & $20(37.0 \%)$ \\
\hline
\end{tabular}


Compared to participants who identified as Black, Asian ( $p$ $<0.001)$, White $(p=0.001)$, and White-Latinx $(p=0.029)$ reported significantly lower medical mistrust. There were no differences for Black-Latinx $(p=0.452)$ or American Indian/ Alaska Native $(p=0.708)$ participants. Black participants reported significantly higher endorsement of health-specific COVID-19 conspiracy beliefs compared to White participants $(p<0.001)$ but did not significantly differ from any other group. Finally, health-specific COVID-19 conspiracy beliefs were associated with significantly lower engagement in COVID-19 protective behaviors $(p<0.001)$, but general medical mistrust was not $(p=0.285)$. Full model results are displayed in Table 4 and Figure 1b.

We also assessed the indirect effects of everyday, structural, and healthcare discrimination, respectively, on COVID-19 protective behaviors. Results indicated that there was no significant specific indirect effect of everyday discrimination on COVID-19 protective behaviors via general medical mistrust $(B(S E)=0.003(0.003), p=0.325,95 \% \mathrm{CI}[-0.002,0.01])$ or via health-specific COVID-19 conspiracy beliefs $(B(S E)=-$ 0.004 (0.003), $p=0.157,95 \%$ CI $[-0.01,0.001])$. Accordingly, the total indirect effect via both medical discrimination and health-specific COVID-19 conspiracy beliefs was also nonsignificant $(B(S E)=-0.001(0.004), p=0.727,95 \%$
CI $[-0.01,0.01])$. Regarding structural discrimination, the indirect effect via health-specific COVID-19 conspiracy beliefs $(B(S E)=-0.03(0.01), p<0.001,95 \% \mathrm{CI}[-0.04,-0.02])$, but not general medical mistrust $(B(S E)=0.000(0.001), p=$ $0.6999,95 \%$ CI $[-0.001,0.002])$, was significant. The total indirect effect was also significant $(B(S E)=-0.03(0.01), p<$ $0.001,95 \%$ CI $[-0.04,-0.02])$, indicating that structural discrimination was associated with lower engagement in COVID-19 protective behaviors via general medical mistrust and health-specific COVID-19 conspiracy beliefs. Similarly, results indicated that the indirect effect of healthcare discrimination via conspiracy beliefs $(B(S E)=-0.01(0.004), p=$ $0.014,95 \%$ CI $[-0.02,-0.003])$ was significant, but was not significant via general medical mistrust $(B(S E)=0.003$ $(0.003), p=0.339,95 \% \mathrm{CI}[-0.002,0.01])$. However, the total indirect effect was not significant $(B(S E)=-0.01(0.004), p=$ $0.078,95 \%$ CI $[-0.02,0.001])$.

\section{Discussion}

In this study, we sought to understand how race and experiences of various forms of discrimination are associated with individuals' medical mistrust. We also investigated how both
Table 4 Path model results $(N=$ 963)

\begin{tabular}{|c|c|c|c|c|}
\hline & $B(S E)$ & $\beta$ & $p$ & $\begin{array}{l}95 \% \text { CI } \\
{[\mathrm{LL}, \mathrm{UL}]}\end{array}$ \\
\hline \multicolumn{5}{|l|}{ Medical mistrust } \\
\hline Everyday discrimination & $0.13(0.03)$ & $0.19(0.05)$ & $<0.001 * *$ & {$[0.11,0.27]$} \\
\hline Structural discrimination & $0.02(0.04)$ & $0.02(0.05)$ & 0.675 & {$[-0.07,0.11]$} \\
\hline Healthcare discrimination & $0.11(0.04)$ & $0.13(0.05)$ & $0.004 * *$ & {$[0.06,0.20]$} \\
\hline Race: Black-Hispanic/Latinx & $0.08(0.11)$ & $0.03(0.04)$ & 0.452 & {$[-0.03,0.09]$} \\
\hline Race: Asian & $-0.24(0.07)$ & $-0.14(0.04)$ & $<0.001 * *$ & {$[-0.20,-0.07]$} \\
\hline Race: White-not Hispanic/Latinx & $-0.24(0.07)$ & $-0.13(0.04)$ & $0.001 * *$ & {$[-0.19,-0.06]$} \\
\hline Race: White-Hispanic/Latinx & $-0.19(0.09)$ & $-0.08(0.04)$ & $0.029 *$ & {$[-0.13,-0.02]$} \\
\hline Race: American Indian/Alaska Native & $-0.04(0.11)$ & $-0.01(0.03)$ & 0.708 & {$[-0.07,0.04]$} \\
\hline \multicolumn{5}{|l|}{ COVID-19 conspiracy theory beliefs } \\
\hline Everyday discrimination & $0.06(0.04)$ & $0.06(0.04)$ & 0.135 & {$[-0.01,0.13]$} \\
\hline Structural discrimination & $0.40(0.04)$ & $0.41(0.04)$ & $<0.001 * *$ & {$[0.34,0.48]$} \\
\hline Healthcare discrimination & $0.14(0.05)$ & $0.11(0.04)$ & $0.003 * *$ & {$[0.05,0.17]$} \\
\hline Race: Black-Hispanic/Latinx & $-0.08(0.13)$ & $-0.02(0.03)$ & 0.520 & {$[-0.07,0.03]$} \\
\hline Race: Asian & $-0.16(0.08)$ & $-0.07(0.03)$ & 0.054 & {$[-0.12,0.01]$} \\
\hline Race: White-not Hispanic/Latinx & $-0.41(0.09)$ & $-0.16(0.03)$ & $<0.001 * *$ & {$[-0.21,-0.10]$} \\
\hline Race: White-Hispanic/Latinx & $-0.17(0.10)$ & $-0.05(0.03)$ & 0.097 & {$[-0.10,0.00]$} \\
\hline Race: American Indian/Alaska Native & $0.03(0.14)$ & $0.01(0.03)$ & 0.856 & {$[-0.04,0.05]$} \\
\hline \multicolumn{5}{|l|}{ COVID-19 protective behaviors } \\
\hline General medical mistrust & $0.02(0.02)$ & $0.18(0.17)$ & 0.285 & {$[-0.10,0.46]$} \\
\hline Health-specific COVID-19 conspiracy beliefs & $-0.08(0.02)$ & $-0.86(0.12)$ & $<0.001 * *$ & {$[-1.04,-0.68]$} \\
\hline
\end{tabular}

Note: $* p<0.05, * * p<0.01$. Analyses statistically control for socioeconomic status. Race: Black-not Hispanic/ Latinx is included as the reference group 
general medical mistrust and health-specific COVID-19 conspiracy beliefs were associated with engagement in COVID19 protective behaviors. Consistent with existing literature, we generally found support for most of our hypotheses.

Results showed that structural discrimination was associated with higher health-specific COVID-19 conspiracy beliefs which was consistent with what was hypothesized. Healthspecific COVID-19 conspiracy beliefs are a symptom of the same issues that marginalized groups experience through structural discrimination. In other words, COVID-19 conspiracy beliefs and structural discrimination are both characterized by a broad mistrust in powers beyond the micro level. This may lead people who already distrust the government to believe in these theories. However, contrary to what we hypothesized, structural discrimination was not associated with general medical mistrust. More research is needed to address the nuances of different forms of discrimination and medical mistrust.

Everyday discrimination was associated with more general medical mistrust but was not associated with health-specific COVID-19 conspiracy beliefs. While everyday discrimination may be a symptom of institutional issues, it is nevertheless perceived as an individual issue [82]. Therefore, although people that experience everyday discrimination are more like to experience more general medical mistrust, they may not necessarily conclude that COVID-19 is a planned genocide by the government or endorse other extreme ideologies associated with health conspiracy theories. Healthcare discrimination was associated with both general medical mistrust and health-specific COVID-19 conspiracy theories which is consistent with past research that has examined the effects of discrimination within the medical sphere and its association with medical mistrust more broadly [33, 38, 53, 57].

Regarding race differences, Black participants reported higher general medical mistrust than Asian, White, and White-Latinx participants, but there were no significant differences for American Indian/Alaska Native or Black-Latinx participants, which reflect the more frequent experiences of discrimination these groups tend to experience in the United States $[63,65,66]$. Findings indicate that Black participants more highly endorsed health-specific COVID-19 conspiracy beliefs than White participants but did not significantly differ from any other racial group [53, 83, 84]. These findings are consistent with past research that has focused exclusively on comparisons between Black and White communities [32-35], and the nonsignificant comparisons also appear to reflect that White Americans have held positions of power in American society and have not been subjected to systemic racial oppression that may result in the belief of these conspiracy theories.

We found no significant interaction between discrimination and race or ethnicity, indicating that the strength of the relationships between discrimination with general medical mistrust and health-specific COVID-19 conspiracy beliefs does not vary as a function of participants' race or ethnicity. This could be due to the fact that the everyday and structural discrimination measures were not specific to racial discrimination exclusively (although this was the most common attribution that participants reported) and higher rates of discrimination may partially reflect experiences based on other identities (e.g., gender, age.).

Consistent with our hypothesis, results suggest that healthspecific COVID-19 conspiracy beliefs are associated with lower engagement in COVID-19 protective behaviors. This is in line with previous literature, which has found that individuals who harbor medical mistrust and endorse conspiracy theories report lower adherence to prescription medication [35] and decreased participation in preventative care [38]. An analysis of the indirect effects of discrimination on COVID-19 protective behaviors via conspiracy beliefs indicates that health discrimination and structural discrimination are associated with decreased engagement in COVID-19 protective behaviors via COVID-19 conspiracy beliefs. This is consistent with the notion that various forms of discrimination contribute a stronger belief in health-specific COVID-19 conspiracy beliefs $[35,37,54,55]$. This may lead to individuals being skeptical of protective behaviors due to the belief that such behaviors and policies are harmful to themselves and their community [31].

Contrary to what we hypothesized, general medical mistrust was not associated with COVID-19 protective behaviors. Although general medical mistrust was not associated with COVID-19 protective behaviors in the current study, past studies have shown that it does affect how often individuals go to the doctor, adhere to medication, and follow physicians' recommendations $[34,54,70]$. The absence of this association could be due to the lack of specificity of the medical mistrust measure. General medical mistrust reflected a broader, more general mistrust of medical systems and therefore is likely a more distal predictor of COVID-19 protective behaviors, compared to endorsement of conspiracy beliefs which were specific to COVID-19.

\section{Strengths, Limitations, and Suggestions for Future Research}

Strengths of this study include the racial diversity of our sample, which allows for greater generalizability of our findings, and the timing of data collection, which occurred in early May 2020, almost 2 months after most states issued stay-athome orders [85]. While most states had stay-at-home orders during this time, not all states issued policies like these [72]. Participants who lived in the few states that did not have the said orders may have perceived the pandemic differently than participants who lived in states that had these orders. Their 
perception of the pandemic could have then altered how they engaged in the protective behavior.

We measured three different forms of discrimination (everyday, structural, and healthcare) and their independent effects on general medical mistrust and health-specific COVID19 conspiracy beliefs. These different forms of discrimination showcase the different experiences marginalized groups may have in society $[58,61]$ and their impact on how these individuals navigate and interact with the medical institution. Although we tried to be inclusive in our assessment of race and ethnicity and separated Black and White participant groups by Latinx ethnic identity, we were not able to do that for all racial groups. For example, if a participant identified as Asian-Latinx, they were only coded as Asian due to low sample size. Further, we recognize that there is substantial heterogeneity within racial and ethnic groups [86, 87], and Latinx is not the only ethnicity with which individuals identify. Finally, participants recruited through MTurk tend to be younger, more educated, and exhibit healthier behavior compared to the general population [88]. In the context of the current study, this could mean that the participants in this study were more likely to engage in COVID-19 protective behaviors than the general population, yielding generalizability concerns.

Because variables were assessed cross-sectionally, we are unable to make conclusions about temporal associations. Future studies should implement qualitative methods to provide depth and nuance to these findings. Because COVID-19 has been politicized, some conspiracy theories that were politically driven (e.g., COVID-19 is a hoax [89]) led some individuals, primarily those who identify as politically conservative, to protest the requirement of masks in public [90]. Although the measure of health-specific COVID-19 conspiracy beliefs in the current study reflected ideas such as COVID-19 being a planned genocide, it is important for future studies to evaluate other conspiracy theory themes (e.g., 5G tower conspiracy theory [91, 92], government inflating infection numbers [93]) and discern how different background characteristics including SES, race, social, and political views differentially contribute to various types of conspiracy beliefs.

\section{Implications}

These results have several implications for medical contexts. This study demonstrates that discrimination does not just have to take place in a medical space for citizens to harbor medical mistrust. Discrimination on both the interpersonal and structural level affect an individuals' health behaviors through medical mistrust [30]. We need to reduce everyday and structural discrimination to improve health disparities in the United States related to racist and discriminatory practices in other sectors such as housing, employment, and education, all of which have been shown to also impact health $[94,95]$.
Society must recognize that historical factors and current discrimination contribute to health disparities. Neglecting this responsibility will lead to continued mistrust which will allow health disparities to persist [96].

At an individual level, medical professionals should acknowledge discriminatory practices and actively work against them. Both implicit and explicit biases have real-world consequences when it comes to patient care [97, 98]. However, bias and discrimination may also be present in the medical institution more broadly [99], which is especially dangerous during a pandemic such as COVID-19 when engaging in protective behaviors is necessary to slow the spread of the virus. Ensuring individuals' safety and adherence to the CDC, WHO, and other health guidelines is virtually impossible if citizens do not trust these institutions. In order to gain the trust of citizens, professionals and organizations should address the concerns these citizens may have by acknowledging healthrelated discrimination, medical conspiracy theories, and their origins [57]. To ensure adherence to protective behaviors, partnerships with trusted organizations and individuals within marginalized communities such as churches, historically Black colleges and universities, and elected officials could help rebuild trust in medical institutions and spread accurate information about the virus [100]. In addition, greater representation of racially minoritized groups within the medical field could also help establish trust in the medical system [40].

\section{Conclusions}

The goal of this study was to examine the role race, ethnicity, and discrimination play in medical mistrust (general and health-specific COVID-19 conspiracy beliefs) and examine if these factors are associated with engagement in COVID19 protective behaviors. Findings indicate that race and various experiences of discrimination provide important context for individuals' endorsement of medical mistrust, which in turn have implications for health behaviors. It is time for medical professionals, public health officials, and institutions to gain back the trust of marginalized groups. By acknowledging this mistrust, being transparent, and making an active effort to eliminate discriminatory practices within and outside of medical institutions, they will be one step closer to eliminating racial health disparities in the United States.

Supplementary Information The online version contains supplementary material available at https://doi.org/10.1007/s40615-021-01080-x.

Author Contribution AS, JW, and AR were responsible for conceptualization. JW and $\mathrm{AH}$ were responsible for data curation, formal analysis, 
and methodology. AS and JW supervised the project. All authors contributed to writing via the original draft and editing.

Funding This study was supported by funds provided by the University of Central Florida Faculty Cluster Initiative.

\section{Declarations}

Ethics Approval This research was approved by the University of Central Florida Institutional Review Board: IRB 00001138; STUDY00001707.

Consent to Participate Freely given, informed consent to participate in the study was obtained from participants.

Competing Interests The authors declare no competing interests.

\section{References}

1. CDC (2020) COVID-19 in racial and ethnic minority groups.

2. Devakumar D, Bhopal SS, Shannon G. COVID-19: the great unequaliser. J R Soc Med. 2020;113:234-5.

3. Vazquez M (2021) Calling COVID-19 the "Wuhan Virus" or "China Virus" is inaccurate and xenophobic. https://medicine. yale.edu/news-article/23074/. Accessed 2 May

4. Price-Haywood EG, Burton J, Fort D, Seoane L. Hospitalization and mortality among Black patients and White patients with Covid-19. N Engl J Med. 2020;382:2534-43.

5. Kim SJ, Bostwick W. Social vulnerability and racial inequality in COVID-19 deaths in Chicago. Health Educ Behav. 2020;47:509 13.

6. Yancy CW. COVID-19 and African Americans. JAMA. 2020;323:1891-2.

7. Webb Hooper M, Nápoles AM, Pérez-Stable EJ. COVID-19 and racial/ethnic disparities. JAMA. 2020;323:2466-7.

8. Millett G, Jones A, Benkeser D, et al. Assessing differential impacts of COVID-19 on Black communities. Ann Epidemiol. 2020;47:37-44. https://doi.org/10.1016/j.annepidem.2020.05. 003

9. Chowkwanyun M, Reed AL. Racial health disparities and Covid19 - caution and context. N Engl J Med. 2020;383:201-3.

10. Silva C (2020) Why Latinx people are hospitalized from COVID19 at 4 times the rate of Whites. In: NPR.org. https://www.npr.org/ sections/coronavirus-live-updates/2020/07/01/885923635/whylatinos-are-hospitalized-from-covid-19-four-times-the-rate-ofwhite-american. Accessed 19 Jan 2021

11. Killerby M, Link-Gelles R, Haight S, et al (2020) Characteristics associated with hospitalization among patients with COVID-19 Metropolitan Atlanta, Georgia, March-April. MMWR Morbidity and Mortality Weekly Report. https://doi.org/10.15585/mmwr. $\mathrm{mm} 6925 \mathrm{e} 1$

12. CDC (2020) Community, Work, and School. In: Centers for Disease Control and Prevention. https://www.cdc.gov/ coronavirus/2019-ncov/community/health-equity/race-ethnicity. html. Accessed 19 Jan 2021

13. Artiga S (2020) Health disparities are a symptom of broader social and economic inequities. KFF

14. Kantamneni N. The impact of the COVID-19 pandemic on marginalized populations in the United States: a research agenda. J Vocat Behav. 2020;119:103439.
15. Jaiswal J, Halkitis P. Towards a more inclusive and dynamic understanding of medical mistrust informed by science. Behav Med. 2019;45:79-85.

16. Govier T. Is it a jungle out there? Trust, distrust and the construction of social reality. Dialogue: Canadian Philosophical Review / Revue canadienne de philosophie. 2010;33:237-52.

17. Armstrong K, McMurphy S, Dean LT, Micco E, Putt M, Halbert $\mathrm{CH}$, et al. Differences in the patterns of health care system distrust between Blacks and Whites. J Gen Intern Med. 2008;23:827-33.

18. CDC (2017) African American Health. In: Centers for Disease Control and Prevention. https://www.cdc.gov/vitalsigns/aahealth/ index.html. Accessed 19 Jan 2021

19. Zhang S, Senteio C, Felizzola J, Rust G. Racial/ethnic disparities in antiretroviral treatment among HIV-infected pregnant Medicaid enrollees, 2005-2007. Am J Public Health. 2013;103:e46-53. https://doi.org/10.2105/AJPH.2013.301328.

20. Adams Portia E. (2012) Beyond individual-level sexual risk behaviors: HIV/AIDS and racial health disparities. In: Sheri R. Notaro (ed) Health Disparities Among Under-served Populations: Implications for Research, Policy and Praxis. Emerald Group Publishing Limited 227-240

21. Mersha T, Abebe T. Self-reported race/ethnicity in the age of genomic research: its potential impact on understanding health disparities. Human Genomics. 2015;9:1

22. Bamshad M, Wooding S, Salisbury B, Stephens J. Deconstructing the relationship between genetics and race. Nat Rev Genet. 2004;5:598-609.

23. Goodman AH. Why genes don't count (for racial differences in health). Am J Public Health. 2000;90:1699-702.

24. Roberts D (2015) The problem with race-based medicine.

25. Washington HA (2006) Medical apartheid: the dark history of medical experimentation on Black Americans from colonial times to the present. Anchor Books, New York

26. Carter R, Lau M, Johnson V, Kirkinis K. Racial discrimination and health outcomes among racial/ethnic minorities: a metaanalytic review. J Multi Counsel Dev. 2017;45:232-59.

27. Paradies Y, Ben J, Denson N, Elias A, Priest N, Pieterse A, et al. Racism as a determinant of health: a systematic review and metaanalysis. PLoS One. 2015;10:e0138511.

28. Gehlert S, Sohmer D, Sacks T, Mininger C, McClintock M, Olopade $\mathrm{O}$. Targeting health disparities: a model linking upstream determinants to downstream interventions. Health Aff. 2008;27: 339-49.

29. Bogart LM, Ojikutu BO, Tyagi K, Klein DJ, Mutchler MG, Dong $\mathrm{L}$, et al. COVID-19 related medical mistrust, health impacts, and potential vaccine hesitancy among Black Americans living with HIV. J Acquir Immune Defic Syndr. 2021;86:200-7.

30. Powell W, Richmond J, Mohottige D, Yen I, Joslyn A, CorbieSmith G. Medical mistrust, racism, and delays in preventive health screening among African-American men. Null. 2019;45:102-17.

31. Earnshaw VA, Bogart LM, Klompas M, Katz IT. Medical mistrust in the context of Ebola: implications for intended care-seeking and quarantine policy support in the United States. J Health Psychol. 2016;24:219-28.

32. Cuevas A, O'Brien K, Saha S. African American experiences in healthcare: I always feel like I'm getting skipped over. Health Psychol. 2016:35:987-95.

33. Shavers V, Fagan P, Jones D, Klein W, Boyington J, Moten C, et al. The state of research on racial/ethnic discrimination in the receipt of health care. Am J Public Health. 2012;102:953-66.

34. Saha S, Jacobs E, Moore R, Beach MC. Trust in physicians and racial disparities in HIV care. AIDS Patient Care STDs. 2010;24: 415-20.

35. Boulware LE, Cooper LA, Ratner LE, LaVeist TA, Powe NR. Race and trust in the health care system. Public Health Rep. 2003;118:358-65. 
36. Davis J, Bynum S, Katz R, Buchanan K, Green BL. Sociodemographic differences in fears and mistrust contributing to unwillingness to participate in cancer screenings. J Health Care Poor Underserved. 2012;23:67-76.

37. Jaiswal J. Whose responsibility is it to dismantle medical mistrust? Future directions for researchers and health care providers. Behav Med. 2019;45:188-96.

38. Hammond W, Matthews D, Mohottige D, Agyemang A, CorbieSmith G. Masculinity, medical mistrust, and preventive health services delays among community-dwelling African-American men. J Gen Intern Med. 2010;25:1300-8.

39. LaVeist TA, Isaac LA, Williams KP. Mistrust of health care organizations is associated with underutilization of health services. Health Serv Res. 2009;44:2093-105.

40. Kennedy B, Mathis C, Woods A. African Americans and their distrust of the health care system: healthcare for diverse populations. J Cult Divers. 2007;14:56-60.

41. Freimuth V, Quinn S, Thomas S, Cole G, Zook E. Duncan T (2001) African Americans' views on research and the Tuskegee Syphilis Study. Soc Sci Med. 1982;52:797-808.

42. Scharff DP, Mathews KJ, Jackson P, Hoffsuemmer J, Martin E, Edwards D. More than Tuskegee: understanding mistrust about research participation. J Health Care Poor Underserved. 2010;21: 879-97.

43. Convicts injected with live cancer cells (1956) 14. The New York Times

44. Miroff N (2020) Hospital where activists say ICE detainees were subjected to hysterectomies says just two were performed there. Washington Post

45. Zingel A (2019) Indigenous women come forward with accounts of forced sterilization, says lawyer | CBC News. In: CBC. https:// www.cbc.ca/news/canada/north/forced-sterilization-lawsuitcould-expand-1.5102981. Accessed 19 Jan 2021

46. Stote K. The coercive sterilization of aboriginal women in Canada. Am Indian Cult Res J. 2012;36:117-50.

47. Tamayo-Sarver JH, Hinze SW, Cydulka RK, Baker DW. Racial and ethnic disparities in emergency department analgesic prescription. Am J Public Health. 2003;93:2067-73.

48. Grady M, Edgar T (2003) Racial disparities in health care: highlights from focus group findings. National Academies Press (US) 1.

49. Mayberry RM, Mili F, Ofili E. Racial and ethnic differences in access to medical care. Med Care Res Rev. 2000;57:108-45.

50. Andrade G. Medical conspiracy theories: cognitive science and implications for ethics. Med Health Care Philos. 2020;23:505-18.

51. Bogart LM, Bird ST. Exploring the relationship of conspiracy beliefs about HIV/AIDS to sexual behaviors and attitudes among African-American adults. J Natl Med Assoc. 2003;95:1057-65.

52. Wood M, Douglas K, Sutton R. Dead and alive: beliefs in contradictory conspiracy theories. Soc Psychol Personal Sci. 2012;3: 767-73. https://doi.org/10.1177/1948550611434786.

53. Davis J, Wetherell G, Henry PJ. Social devaluation of African Americans and race-related conspiracy theories. Eur J Soc Psychol. 2018;48:999-1010.

54. Williamson LD, Smith MA, Bigman CA. Does discrimination breed mistrust? Examining the role of mediated and nonmediated discrimination experiences in medical mistrust. Null. 2019;24:791-9.

55. Durant RW, Legedza AT, Marcantonio ER, Freeman MB, Landon BE. Different types of distrust in clinical research among whites and African Americans. J Natl Med Assoc. 2011;103:12330.

56. Oakley L, Harvey S, López-Cevallos D. Racial and ethnic discrimination, medical mistrust, and satisfaction with birth control services among young adult Latinas. Womens Health Issues. 2018;28:313-20. https://doi.org/10.1016/j.whi.2018.03.007.
57. Gaston GB, Alleyne-Green B. The impact of African Americans' beliefs about HIV medical care on treatment adherence: a systematic review and recommendations for interventions. AIDS Behav. 2013;17:31-40.

58. Kessler R, Mickelson K, Williams D. The prevalence, distribution, and mental health correlates of perceived discrimination in the United States. J Health Soc Behav. 1999;40:208-30.

59. Quinn KG, Kelly JA, DiFranceisco WJ, Tarima SS, Petroll AE, Sanders C, et al. The health and sociocultural correlates of AIDS genocidal beliefs and medical mistrust among African American MSM. AIDS Behav. 2018;22:1814-25.

60. Koss CS, Baker TA. A question of trust: does mistrust or perceived discrimination account for race disparities in advance directive completion? Innov Aging. 2017;1. https://doi.org/10.1093/ geroni/igx017.

61. Williams DR, Yu Y, Jackson JS, Anderson NB. Racial differences in physical and mental health: socio-economic status, stress and discrimination. J Health Psychol. 1997;2:335-51.

62. Williams DR, Mohammed SA. Discrimination and racial disparities in health: evidence and needed research. J Behav Med. 2009;32:20-47.

63. Findling M, Casey L, Fryberg S, Hafner S, Blendon R, Benson J, et al. Discrimination in the United States: experiences of Native Americans. Health Serv Res. 2019;54:1431-41. https://doi.org/ 10.1111/1475-6773.13224.

64. Lee DL, Ahn S. Racial discrimination and Asian mental health: a meta-analysis. Couns Psychol. 2011;39:463-89.

65. Gee GC, Delva J, Takeuchi DT. Relationships between selfreported unfair treatment and prescription medication use, illicit drug use, and alcohol dependence among Filipino Americans. Am J Public Health. 2007;97:933-40.

66. Jang Y, Kim G, Chiriboga D. Health, healthcare utilization, and satisfaction with service: barriers and facilitators for older Korean Americans. J Am Geriatr Soc. 2005;53:1613-7.

67. Guadagnolo BA, Cina K, Helbig P, Molloy K, Reiner M, Cook $\mathrm{EF}$, et al. Medical mistrust and less satisfaction with health care among Native Americans presenting for cancer treatment. J Health Care Poor Underserved. 2009;20:210-26.

68. Thorburn S, Kue J, Keon KL, Lo P. Medical mistrust and discrimination in health care: a qualitative study of Hmong women and men. J Community Health. 2012;37:822-9.

69. Armstrong K, Ravenell KL, McMurphy S, Putt M. Racial/ethnic differences in physician distrust in the United States. Am J Public Health. 2007;97:1283-9.

70. Wasserman J, Flannery MA, Clair JM. Raising the ivory tower: the production of knowledge and distrust of medicine among African Americans. J Med Ethics. 2007;33:177-80.

71. Schumaker E (2020) Here are the states that have shut down nonessential businesses. In: ABC News. https://abcnews.go.com/ Health/states-shut-essential-businesses-map/story?id=69770806. Accessed 19 Jan 2021

72. Wu J, Smith S, Khurana M, Siemaszko C, DeJesus-Banos B (2020) Here are the stay-at-home orders in every state. In: NBC News. https://www.nbcnews.com/health/health-news/here-arestay-home-orders-across-country-n1168736. Accessed 16 Mar 2021

73. Grant BF, Goldstein RB, Saha TD, Chou SP, Jung J, Zhang H, et al. Epidemiology of DSM-5 alcohol use disorder: results from the National Epidemiologic Survey on Alcohol and Related Conditions III. JAMA Psychiatry. 2015;72:757-66.

74. Adler N, Castellazzo G, Ickovics J. Relationship of subjective and objective social status with psychological and physiological functioning: preliminary data in healthy White women Health Psychology Official. J Div Health Psyc Am Psychol Asso. 2000;19:586-92. 
75. Bogart L, Thorburn S. Are HIV/AIDS conspiracy beliefs a barrier to HIV prevention among African Americans? J Acquir Immune Defic Syndr. 2005;38(1999):213-8.

76. Phelan JC, Link BG. Is racism a fundamental cause of inequalities in health? Annu Rev Sociol. 2015;41:311-30.

77. DeNavas-Walt C, Proctor B, Smith J (2007) Income, poverty, and health insurance coverage in the United States.

78. Bogart LM, Galvan FH, Wagner GJ, Klein DJ. Longitudinal association of HIV conspiracy beliefs with sexual risk among black males living with HIV. AIDS Behav. 2011;15:1180-6.

79. Idan E, Xing A, Ivory J, Alsan M. Sociodemographic correlates of medical mistrust among African American men living in the East Bay. J Health Care Poor Underserved. 2020;31:115-27.

80. Hayes AF (2013) Introduction to mediation, moderation, and conditional process analysis: a regression-based approach. xvii, 507

81. Muthén L, Muthén B (2018) Mplus: the comprehensive modeling program for applied researchers: users guide. Guilford publications, Los Angeles

82. Breen N, Landrine H, Reeve B, et al. Measuring individual-level racism/discrimination: the state of the art. Du Bois Review. 2010;8:159-77.

83. Bogart LM, Thorburn S. Relationship of African Americans' sociodemographic characteristics to belief in conspiracies about HIV/AIDS and birth control. J Natl Med Assoc. 2006;98:114450.

84. Ross MW, Essien EJ, Torres I. Conspiracy beliefs about the origin of HIV/AIDS in four racial/ethnic groups. J Acquir Immune Defic Syndr. 2006;41:342-4.

85. Mervosh S, Lu D, Swales V (2020) See which states and cities have told residents to stay at home - The New York Times. https:// www.nytimes.com/interactive/2020/us/coronavirus-stay-athome-order.html. Accessed 19 Jan 2021

86. Burlew A, Peteet B, Mccuistian C, Miller-Roenigk B. Best practices for researching diverse groups. Am J Orthopsychiatry. 2019;89:354-68.

87. Burlew AK, Weekes JC, Montgomery L, Feaster DJ, Robbins MS, Rosa CL, et al. Conducting research with racial/ethnic minorities: methodological lessons from the NIDA Clinical Trials Network. Null. 2011;37:324-32.

88. Walters K, Christakis DA, Wright DR. Are Mechanical Turk worker samples representative of health status and health behaviors in the U.S.? PLoS One. 2018;13:e198835.

89. Uscinski JE, Enders AM, Klofstad C, Seelig M, Funchion J, Everett C, Wuchty S, Premaratne K, Murthi M (2020) Why do people believe COVID-19 conspiracy theories? Harvard Kennedy
School Misinformation Review. https://doi.org/10.37016/mr2020-015

90. Aratani L (2020) How did face masks become a political issue in America? The Guardian

91. Nakashima E (2020) DHS to advise telecom firms on preventing $5 \mathrm{G}$ cell tower attacks linked to coronavirus conspiracy theories. Washington Post

92. Destiny T (2020) Conspiracy theories about 5G networks have skyrocketed since COVID-19. In: The Conversation. http:// theconversation.com/conspiracy-theories-about-5g-networkshave-skyrocketed-since-covid-19-139374. Accessed 19 Jan 2021

93. Perez M (2020) Death toll conspiracy: why conservative mediaand soon, possibly Trump - are doubting coronavirus mortality figures. In: Forbes. https://www.forbes.com/sites/mattperez/ 2020/05/10/death-toll-conspiracy-why-conservative-media-andsoon-possibly-trump-are-doubting-coronavirus-mortalityfigures/. Accessed 19 Jan 2021

94. Yearby R. Racial disparities in health status and access to healthcare: the continuation of inequality in the United States due to structural racism: continuing racial health disparities. Am J Econ Sociol. 2018;77:1113-52.

95. Feagin J, Bennefield Z. Systemic racism and U.S. health care. Soc Sci Med. 2014;103(1982):7-14.

96. Jaiswal J, LoSchiavo C, Perlman DC. Disinformation, misinformation and inequality-driven mistrust in the time of COVID-19: lessons unlearned from AIDS denialism. AIDS Behav. 2020;24: 2776-80.

97. FitzGerald C, Hurst S. Implicit bias in healthcare professionals: a systematic review. BMC Medical Ethics. 2017;18:19. https://doi. org/10.1186/s12910-017-0179-8.

98. Penner L, Dovidio J, Gonzalez R, et al. The effects of oncologist implicit racial bias in racially discordant oncology interactions. J Am Soc Clin Oncol. 2016;34:2874-80. https://doi.org/10.1200/ JCO.2015.66.3658.

99. Hardeman RR, Medina EM, Kozhimannil KB. Structural racism and supporting Black lives - the role of health professionals. N Engl J Med. 2016;375:2113-5.

100. Ollove M, Vestal C (2020) COVID-19 is crushing Black communities. Some states are paying attention. https://pew.org/3esmcxz. Accessed 19 Jan 2021

Publisher's Note Springer Nature remains neutral with regard to jurisdictional claims in published maps and institutional affiliations. 